\title{
School Dental Health Programs
}

\section{Don. P. Haefner, Ph.D. University of Michigan School of Public Health}

In principle, dental health education in the school setting should be an extremely important component of efforts to influence preventive dental behavior. For one thing, the other major approaches are of necessarily limited scope or efficacy. Take the dental office for example: In one study, over 40 percent of the dentists surveyed admitted that they themselves did not attempt to educate patients routinely in their own offices although they overwhelmingly recognized the importance of doing so. ${ }^{13}$ In addition, nearly two thirds of the dental hygienists questioned reported spending less than 30 percent of their time on diet and oral hygiene instruction.

Even when the dentist does function as a dental health educator, the kind of education he provides in the treatment setting may be limited, with emphasis on the patient's current oral problem rather than on dental health in general. Furthermore, only about half the American public visit the dentist in a given year which limits the scope of coverage of the general population. ${ }^{14}$

Another approach that has been suggested to inform the public about dental health and to lead it to take appropriate preventive action is that of community educational campaigns via the mass media. Unfortunately, however, research studies have found educational campaigns to have varying and often limited effects. Cartwright has noted that many organizations have placed great reliance on media campaigns that do not succeed in producing the desired behaviors among any substantial proportion of the population.' Indeed, he has noted that significant behavioral changes resulting from such campaigns are the exception rather than the rule. A number of factors have been found to limit sharply the degree of success.1,6 For example, people selectively attend to and interpret the contents of mass media communications. In addition, in the mass media situation as it presently exists, there is no opportunity for feedback from the audience (although cable television possesses the potential for such audience response). And all too often, the recommendations of such mass messages are so nonspecific as to have limited impact.

Why might one expect any better outcome from efforts to influence preventive dental behavior made in the school setting? The reasons for a more hopeful view are twofold: First, the school setting avoids the limitations associated with the dental office and with mass campaigns and second, the school setting possesses several positive features in its own right. One great asset is the opportunity for communication with nearly all persons within the entire school-age group in an explicitly educational context where learning is emphasized and rewarded. 
Furthermore, continuing educational influence can be exerted on the target audience over a considerable time period. The process can begin at an early age, when habit patterns are still in the process of being formed rather than being firmly established and resistant to change, as is true of adults. Another advantage is that the dental health educator can use both mass communication and personal communication approaches on the same audience, deriving the maximum benefit from each. The school classroom setting also offers the possibility of making use of the powerful forces of group dynamics in inducing students to take appropriate dental health actions. Clearly, these are powerful advantages; one might anticipate that they would produce highly successful results. To what extent have such expectations been realized?

\section{CURRENT STATUS OF SCHOOL DENTAL HEALTH EDUCATION}

Young has noted that there has been wide recognition of the need for dental health education programs in schools and that dental health has been one of the most frequently included topics in health curricula.22 Unfortunately, however, dental health educational efforts in schools have not yielded results commensurate with their apparent potential. ${ }^{16,22}$ They occupy a low priority in the view of many schools and are a frequent target of proposed budget cuts. By and large, they appear to have achieved relatively poor results in terms of demonstrable, sustained dental health benefits. Although there has been an instructional emphasis, most of the data indicates that students do not engage in the behaviors they have learned.22 And where successes have been achieved, the particular reason for such success is not always clearcut. ${ }^{16}$

How can we account for this unsatisfactory state of affairs? In my view, a few major factors seem to be of particular importance. Among these are overemphasis on the acquisition of information rather than change in behavior; focus on classroom activity even though good oral hygiene performance in the home should be a key goal; lack of emphasis on maintaining changes produced by the educational program; failure to view the school-based dental health educational effort in a sufficiently broad perspective; and less than optimal program planning and evaluation. Let us now examine these factors in somewhat greater detail.

\section{Persuasion vs Information}

The idea that simply presenting information will necessarily lead to some desired outcome has persisted in spite of substantial research evidence showing that it is likely to result in action only on the part of those already predisposed to do so. Rayner and Cohen, ${ }^{16}$ Cohen and Lucye, ${ }^{2}$ Young, ${ }^{22}$ and Kegeles ${ }^{8}$ have all emphasized the need to go 
beyond the presentation of information and facts and motivate individuals in the classroom to learn and subsequently perform healthful behaviors. The phrase "motivate individuals" should not be taken to mean simply combining the presentation of information with exhortation to do the "right" thing. Rather, it refers to inducing a person to act on the basis of some desired goal whose attainment the individual sees as being facilitated by that behavior. The desired goal may be to attain something positive or to avoid something negative. It seems possible that dental health educators may present content that students do not relate to their own goals. If so, the response to the attempted persuasion may be only situationally determined and not persist outside the immediate classroom situation. This poses substantial problems for efforts to elicit changes in beliefs and behavior not only in the classroom but more importantly in the home setting.

Kelman has pointed out three processes which may be involved when one person is influenced by another. He distinguishes among compliance, identification, and internalization by the recipient of the influence attempt. ${ }^{9}$ Compliance occurs when an individual accepts influence because he hopes to achieve a favorable reaction from the source of influence. He does not necessarily believe the content of his induced response; but he does believe that making the response is necessary to be rewarded by the other. Identification occurs when a person adopts behavior like that of another person or group with which he desires to establish or maintain a positive relationship. As with compliance, the adoption of the particular behavior or attitude is motivated by a desire to be liked by the source. Both these types of influence have similar effects on behavior and attitudes. The compliant individual will drop the acquired belief or behavior when it no longer achieves the goal of eliciting a favorable reaction from the source. As the source with whom the individual identifies changes, so will his behaviors and attitudes change because they are tied to the external source and dependent on social support. Internalization, on the other hand, occurs when the individual accepts influence because the attitude or behavior being induced is consistent with his own set of values. In other words, the content of the change is intrinsically rewarding. This type of influence process is much more likely to be maintained over time than that of the other two processes. The individual motivated by internalization will give up an internalized behavior or attitude only when his views change as to the manner in which his values may be maximized.

I feel that Kelman's formulation contains insights that supplement and complement the emphasis on behavior change by the authors cited earlier. I heartily concur with the conviction of these authors that teaching information is not necessary for, and will not necessarily result in, the acquisition of particular behaviors. Following Kelman's analysis, 
however, it seems to me desirable to work toward producing behavioral change on the basis of internalization rather than settling for its acquisition on the basis of compliance or identification. That is, the dental health educational effort should ideally be trying to produce students who end up performing the desired actions regularly on the basis of these actions being congruent with their own values.

\section{Source of the Communication}

Let us now consider some additional communication factors that can importantly affect the outcome of school dental health education. One such factor is the source of the educational attempt. Research on persuasive communication has revealed that the credibility of the communicator as viewed by the recipient of the communication can make a significant difference in acceptance of the message.16 This immediately raises a question as to the most appropriate source of classroom instruction in dental health in order to achieve maximum acceptance.

Two plausible but opposite viewpoints are typified by the approaches of Muhler and his colleagues on the one hand and Masters on the other. ${ }^{4,7,11}$ Muhler and his colleagues have stressed the indispensability of the dentist as a source of motivation for students and have therefore recommended that a dentist conduct the school dental health program. Masters, on the other hand, has devised a detailed program of school dental health education that depends heavily on instruction by regular classroom teachers. Other points of view also exist - for example, use of dental hygienists, ${ }^{12}$ combined efforts of classroom teachers and dental health professionals, and the like. Clearly, there is a range of firmly held opinion as to what should be the most effective source of dental health instruction. Few results of classroom programs, however, have been shown to be of such efficacy as to argue strongly for the clearcut superiority of one source or another. The adequacy of representing the various types of instructional sources in programs and studies also remains in question.

\section{Characteristics of Students}

Another set of factors that clearly seems important in determining the impact of efforts at school dental health education is that of the characteristics of the target audience of such efforts. A number of research studies have shown that socioeconomic status is importantly related to both the possession of particular patterns of health beliefs and to the utilization of health services. ${ }^{18}$ Such factors as one's perceived vulnerability to illness, the perceived efficacy of taking preventive action, and a subjective time horizon oriented toward the future are typically found to a lesser degree among individuals of lower socioeconomic status. Unfortunately, these are the same persons among 
whom medical and dental problems are likely to be particularly pronounced and for whom such beliefs would be desirable. It is important to recognize and take this point into account.

Preventively oriented dental health education programs likely to emphasize the kinds of factors that I just indicated are in short supply among a substantial segment of our population. Such an emphasis is, therefore, likely to receive little social support from the children's own social groups, including that of the family. Several studies have cited the importance of the parent's role, particularly that of the mother, in influencing children's health behavior. ${ }^{10,19,20} \mathrm{~A}$ few research studies also attest to the impact of involving the parents on the overall success of dental health education efforts. ${ }^{3,7}$ Yet school programs in dental health education all too often fail to make systematic use of this factor; they concentrate almost exclusively on children and in so doing make their task more difficult.

Another key source of social influence is that of the peer group, which is particularly important with teenagers. ${ }^{\text {Is }}$ Dental health education efforts in schools, however well conceived, will have difficulty in changing either dental health attitudes or behaviors if there is strong peer group pressure against them.

\section{Transfer From School To Home}

In addition to establishing supportive group standards, it is important that the classroom teaching be so done as to facilitate easy transfer to the home care setting and to maximize the likelihood that the newly changed behaviors will be retained rather than reverting to their former state. All too often, health educational efforts seem to have a sharply limited time dimension; this may account in large part for the failure to maintain over any appreciable period of time whatever gains have initially been realized. This seems to have at least two implications: First, the teaching of desired dental health practices needs to contain some components that will permit effective self-appraisal and selfreinforcement by the student in the home setting. Second, the educational efforts should be so paced as to involve follow-up and reinforcement by the school over time until the newly acquired habit is firmly established. The principles and techniques of behavior modification provide a promising approach to dealing with such problems." It should be noted, however, that applying such techniques in a natural setting such as the school or home is substantially different from doing so in the research laboratory and should not be expected to produce automatic success. ${ }^{17}$

\section{PROGRAM EVALUATION}

One thing that appears to be generally lacking in school dental health educational efforts is systematic program evaluation. ${ }^{16,22}$ I am aware, of 
course, that any analysis of the outcome of a dental health education program that uses either a true control group or a comparison group represents an attempt at evaluation. What I'm talking about, though, goes beyond merely assessing whether the particular educational program produced an outcome different from that of some other program or of no program at all. That type of analysis fails to deal adequately with the program process and fails to yield information that is crucial for understanding program success or failure. Two of my colleagues, Deniston and Rosenstock, have devoted considerable effort to a conceptual analysis of the evaluation process and to the development and application of effective methods of evaluation based upon this formulation. They emphasize the need for specifying the ultimate objectives of the program, the subobjectives whose attainment is needed to reach the ultimate objectives, the activities whose performance is necessary to attain a given subobjective, and the resources allocated to perform these activities.

Deniston and Rosenstock make two points that $I$ would particularly like to emphasize: First, the performance of activities is not necessarily the same thing as the attainment of subobjectives; it is possible to perform the former without necessarily achieving the latter. This distinction is sometimes missed by program operators who confuse the one with the other. Second, some of the things that are done to achieve particular program subobjectives (and hopefully the ultimate objectives), rest on what they label "validity assumptions," i.e., assumptions that doing a particular thing will have a positive effect on a particular outcome. Sometimes these validity assumptions are demonstrably true, while other times the assumptions are based on faith not fact. If one's validity assumptions are incorrect, then performing apparently appropriate activities may fail to result in the attainment of desired subobjectives or ultimate objectives.

Let me illustrate this point by applying it to the evaluation of educational efforts. The ultimate objective to be attained by a dental health education program is, of course, a health outcome - i.e., improved oral health status. But it is not appropriate to evaluate the impact of the educational activities in terms of the ultimate health objective. Why not? Because implicit in the program is the validity assumption that getting students to perform oral self-care at home in a particular manner (a subobjective), is directly linked with attainment of the dental health ultimate objective. This assumption may or may not be true, as appears evident from disagreements in the dental literature and variation over the years in recommended home oral hygiene practices. Rather, the criterion of effectiveness needs to be the extent to which the educational program induces people to take the actions it advocates. From my preceding remarks, it should be evident that program planning and evaluation should include specification of program 
components, including validity assumptions, both to account for a given program outcome and to provide essential information for program improvement.

\section{SUGGESTIONS FOR FUTURE STUDIES}

Based on the analysis presented in this paper, a number of areas seem to warrant further research study, among them the following:

1. The effect of parental involvement in dental health education programs, including the usefulness of various methods to induce such involvement.

2. The impact of various communication sources: classroom teacher, dentist, hygienist, etc. on acceptance and application of preventive recommendations.

3. Information acquisition vs motor skill training - how much of each is necessary/optimal for improving home oral care?

4. Use of behavioral science technology to improve both initial and sustained program outcomes.

5. Application of program evaluation models both to planning of programs and analysis of their outcomes.

In closing, may I suggest that to exploit fully the potential of dental health education in the schools, the combined efforts of many groups teachers, health educators, parents, dental professionals, and behavioral scientists - are needed, drawing upon the unique competencies and insights of each.

\section{REFERENCES}

1. Cartwright D: Some principles of mass persuasion. Human Relations 2:253-267, 1949.

2. Cohen LK, Lucye H: A position on school dental health education. I Sch Health 40:361-365, 1970.

3. Deniston OL, Rosenstock IM: Evaluating health programs. Public Health Rep 85:835-840, 1970.

4. Dudding NJ, Muhler JC: What motivates children to practice good oral hygiene? Periodont 31:141-142, 1960.

5. Gray AS, Hawk DR: An evaluation of a Grade One dental health program. Can J Public Health 59:166-168, 1968.

6. Griffiths $W$, Knutson AL: The role of mass media in public health. Amer J Public Health 50:515-523, 1960.

7. Johns CK, Muhler JC: Can dental health education reduce permanent tooth loss? J Amer Dent Assoc 71:35-38, 1965.

8. Kegeles SS: Blocks to adequate oral health: Current status and means by which they may be overcome. Position paper, Status of Oral Health, Division of Dental Health, Public Health Service, 1973.

9. Kelman HC: Processes of opinion change. Public Opinion Quart 25:57-78, Spring 1961.

10. Kriesberg L, Treiman BR: Preventive utilization of dentists' services among teenagers. J Amer Coll Dent 29:28-45, 1962.

11. Masters DH: The classroom teacher....effective dental health educator. J Sch Health 42:257-261, 1972. 
12. Meyers SE, Downs RA: Comparative findirgs in school systems with differing approaches to dental health education. J Sch Health 38:604-610, 1968.

13. National Opinion Research Center: Factors associated with preventive dental practice. Report No. 69, National Opinion Research Center, University of Chicago, 1959, pp 27-31.

14. O'Shea RM, Gray SB: Dental patients' attitudes and behavior concerning prevention. Public Health Rep 83:405-410, 1968.

15. Ramirez A, Connor RB, Gibbs RM, Griggs HG, Nielson LO, Reeder OW: The effects of different persuasive communications on oral hygiene. University of Alabama, School of Dentistry, 1969.

16. Rayner J, Cohen LK: School dental health education. In Richards ND, Cohen LK (eds): Social Sciences and Dentistry: A Critical Bibliography. Federation Dentaire Internationale, 1971, pp 275-307.

17. Rizley R, Reppucci ND: Behavior modification in the natural environment: A not-soclockwork orange. Upublished paper presented at the American Psychological Association meeting. Montreal, Canada, 1973.

18. Rosenstock IM: Why people use health services. Milbank Mem Fund $Q$ 44:94-127, 1966.

19. Signorile V, Rayner JF, Richards LG: Dental hygiene in the family setting. IADR Abstracts, No. 7, 1968.

20. Tyroler HA, Johnson AL, Fulton JT: Patterns of preventive health behavior in populations. J Health Hum Behav 6:128-140, 1965.

21. Weisenberg M: Behavioral motivation. J Periodont 44:489-499, 1973.

22. Young MAC: Dental health education: An overview of selected concepts and principles relevant to programme planning. Int J Health Educ 13:2-26, 1970. 